\title{
Factors associated with menstrual cycle irregularity and menopause
}

\author{
Jinju Bae ${ }^{\dagger}$, Susan Park ${ }^{\dagger}$ and Jin-Won Kwon ${ }^{*}$ (D)
}

\begin{abstract}
Background: A regular menstrual cycle is an important indicator of a healthy reproductive system. Previous studies reported obesity, stress, and smoking as the factors that are associated with irregular menstruation and early menopause. However, the integrative effects of these modifiable risk factors have not been fully understood. This study aimed to investigate the modifiable risk factors of menstrual cycle irregularity and premature menopause, as well as their individual and combined effects among adult women in Korea.

Method: This study selected adult women aged 19 years and above who had been included in the 2007-2014 Korean National Health and Nutrition Examination Survey. We used a separate dataset to analyze the risk factors of menstrual cycle irregularity and menopause (pre- and postmenopausal women: $n=4788$ and $n=10,697$, respectively). Univariate and multiple logistic regression analyses were conducted to evaluate the effects of smoking, drinking, obesity, and perceived level of stress on the menstrual cycle and menopause. Both logit and linear models were used in the analyses of the association between smoking and menopausal age. Equivalized household income, marital status, and educational level were considered as covariates. The modifiable risk factor scores were also calculated to integrate the effect of smoking, drinking, and obesity in the analysis.

Result: Results showed that smoking status, pack-year, obesity, and perceived level of stress were significantly associated with irregular menstruation among premenopausal women. Especially, women demonstrating $>3$ modifiable risk factor scores had 1.7 times higher risk of having irregular menstruation than those who had a 0 score. Meanwhile, early initiation of smoking ( $\leq 19$ years) and high pack-year $(\geq 5)$ were also significantly associated with premature menopause among postmenopausal women.

Conclusion: This study demonstrated that modifiable risk factors, such as smoking, obesity, and stress, were significantly associated with menstrual cycle irregularity. Lifetime smoking was also correlated with early menopause. Our results suggested that healthier lifestyle practices, including, cessation of smoking, weight control, and stress management, were important factors in improving the reproductive health of women throughout life.
\end{abstract}

Keywords: Irregular menstruation, Premature menopause, Smoking, Obesity, Stress

\section{Background}

Menstruation is an important indicator of possible pregnancy as well as the reproductive health of women. The increasing prevalence of infertility and low fertility associated with age among women in the Korean society has generated significant interest. In fact, in 2014, the number of women who had difficulties in getting pregnant rose to 160,000 , which accounted to an approximate increase of $65 \%$ over the past decade. Additionally, studies

\footnotetext{
* Correspondence: jwkwon@knu.ac.kr

${ }^{\dagger}$ Equal contributors

College of Pharmacy and Research Institute of Pharmaceutical Sciences, Kyungpook National University, 80 Daehak-ro, Daegu 41566, South Korea
}

on the possible relationship between exposure to various diseases and irregular menstrual cycles or early-onset menopausal symptoms among menopausal women have been conducted [1-5].

A variety of hormones affects the menstrual cycle. Irregular menstrual cycle is a major symptom of anovulation, a phenomenon that is accompanied by decreased ovarian steroid secretion and production [6-9]. The most important cause of menstrual cycle irregularity is functional hypothalamic amenorrhea associated with decreased gonadotropin-releasing hormone secretion and hypothalamic-pituitary-adrenal (HPA) axis dysregulation [10-13]. 
The occurrence of these hormonal problems may lead to the development of various chronic diseases, including, infertility, heart disease, and type 2 diabetes $[4,14-16]$. Moreover, the continuation of menstrual cycle irregularities occurring over long periods can result in early onset of menopause. Previous studies have shown that premature menopause increases the risk of heart disease and osteoporosis [1-3].

Irregular menstruation and early menopause may be affected by several factors, including, modifiable risk factors. Studies have shown that the changes in the female hormone levels are associated with health behaviors, obesity, and stress. For example, one study demonstrated that smoking can cause hypoestrogenism [17]. Furthermore, high stress has been shown to affect the HPA axis activity [18], whereas high BMI has been demonstrated to influence the sex hormone-binding globulin (SHBG), free androgen index (FAI), testosterone, and insulin levels [19]. Thus, previous studies have reported a significant association between lifestyle and menstruation [20-25]. However, while most of these studies on menstruation and menopause have been conducted in western countries [22], only a few have been performed in Asia, where women have relatively low BMI and smoking prevalence $[26,27]$. Therefore, this study aimed to investigate the effects of modifiable risk factors on the menopausal irregularities and premature menopause in view of public health.

\section{Method}

\section{Database}

This study used the data of the 4th and 5th cycles (2007-2012) and the 1st and 2nd years (2013-2014) of the 6th cycle of the Korea National Health and Nutrition Examination Survey (KNHANES). The KNHANES was conducted to assess the health and nutritional status of Koreans and monitor the trends in health risk factors and prevalence of major chronic diseases to obtain data that will be used for the development and evaluation of health policies and programs in Korea. KNHANES was designed by complex, multistage, probability sampling to be representative of the civilian, non-institutionalized Korea population. In the case of 2011 survey, the sampling was carried out in two stages: i) selecting a sample of 192 primary sampling units (PSUs) in the whole country (approximately 200,000 PSUs); and ii) systematic sampling of 20 households among each PSU that consisted of an average of 60 households. All people in the selected households were eligible for the KNHANES. The data were collected from the medical check-ups and surveys on health and nutritional status. Informed consent were obtained from the participants who underwent medical check-ups, and the research scheme and data collection methods was approved by the Ethics Committee.
The KNHANES data is open to the public through the website of the Korean Center for Disease Control (KCDC) after anonymization [28].

\section{Study participants}

Although the occurrence of early menopause among the participants was examined from 2007 to 2014, the existence of menstrual cycle irregularity was assessed only from 2010 to 2012. A total of 4788 out of 13,918 women who participated in the survey from 2010 to 2012 were included in the analysis to investigate the risk factors of menstrual cycle irregularity after the exclusion of women who were aged under 19 years $(n=2780)$, did not answer the question on irregular menstrual status, or were already menopaused $(n=6350)$. To analyze the menopausal status, 10,697 out of 36,017 women included in the KNHANES survey from 2007 to 2014 were selected following the exclusion of those who were aged under 19 years $(n=7522)$ and had missing data on menopausal status or artificial menopause $(n=17798)$. Furthermore, we excluded the women who participated in the 20132014 KNHANES survey in the analysis of association between smoking (age at smoking initiation and pack-year) and menopause because the age of smoking initiation was not surveyed in those periods. Lastly, we included 7001 women whose menarche age data were available in the analysis of the association between menopausal and menarche ages.

\section{Variables}

The presence of menstrual cycle irregularity, menopausal age, and menarche age were determined using self-reported questionnaire. The question used to determine the existence of menstrual cycle irregularity was, "Do you currently have a regular menstrual cycle?" Meanwhile, the question used to identify the menarche age was, "When did you have your first menstruation?" For the question on menopausal age, the participants were initially asked whether they had amenorrhea or not. Subsequently, they were asked on the cause and age of onset of their amenorrhea. We only used the data on menopausal age of the participants who placed a check on the natural menopause category.

The participants were categorized based on their smoking status, that is, current smokers, ex-smokers, and non-smokers. Secondhand smoking was assessed using the following self-reported questionnaires: "How many hours a day are you exposed to tobacco smoke at home?" and "How many hours a day are you exposed to tobacco smoke in your workplace?" Then we categorized the total exposure time at home or in their workplaces into 3 groups as follows: no, $<1 \mathrm{~h}$, and $\geq 1 \mathrm{~h}$. Age at smoking initiation was identified using the following self-reported questionnaire: "When did you smoke a 


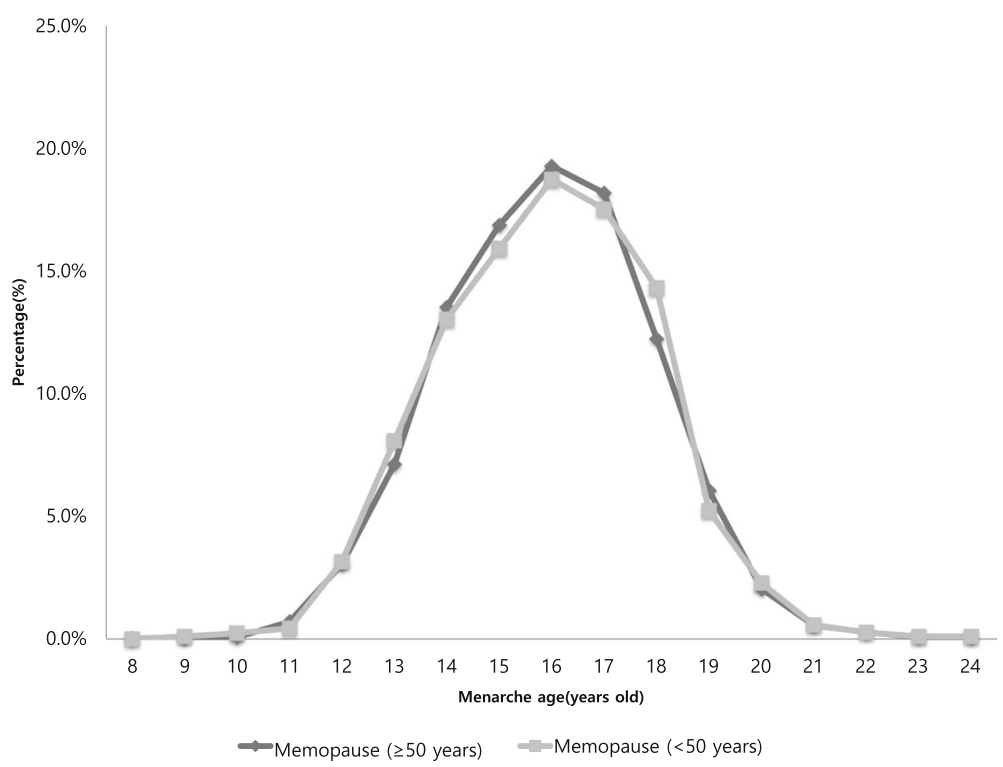

Fig. 1 Distributions of menarche age by group of menopausal age (KNHANES, 2010-2014)

total of one cigarette?" Cigarettes per day and pack-year were counted for ex- and current smokers, including those who were daily and occasional smokers. The packyear was calculated by multiplying the packs smoked per day ( 1 pack $=20$ cigarettes) by years as a smoker. Additionally, the participants were divided into the following five groups based on their frequency of alcohol consumption: $0, \leq 1$ time a month, $2-4$ times a month, $2-3$ times a week, and $\geq 4$ times a week. The participants were also categorized into the following five groups based on their BMI and in accordance with the Asian obesity guideline: underweight ( 0 to $<18.5)$, normal weight $(18.5$ to $<23)$, overweight $(23$ to $<25)$, obese I $(25$ to $<30)$, and obese II $(\geq 30)$. Moreover, the participants were asked on their perceived level of stress using the question "How much do you feel stress generally in your daily life?" with responses such as "few," "a little," "much," and "very much." Meanwhile, the area of residence of the participants was categorized into rural or urban area based on the administrative district. The equivalized household income was calculated by dividing the household income with the square root of the number of household members; subsequently, the income was grouped into quartiles. The participants were also categorized based on their marital status, that is, nonmarried or married. Furthermore, they were grouped into four based on their educational level: elementary undergraduate or middle school, high school, and college or university graduate. The participants who were unable to graduate were categorized into the lower educational level group.

Modifiable risk factor scores were assigned for the integrated variables, including smoking status, BMI, and alcohol consumption frequency. The scores were given as follows: 0 point each for non-smokers, BMI ranges from underweight to overweight ( 0 to $<25 \mathrm{BMI})$, and nondrinkers; 1 point each for ex-smokers, obesity I (25 to $<30$ ), and 1-4 times per month alcohol consumption frequency; and 2 points each current smoker, obesity II ( $\geq 30 \mathrm{BMI})$, and $\geq 2$ times a week alcohol consumption frequency. Subsequently, we summed the given scores and categorized these scores into four groups $(0,1,2, \geq 3)$.

\section{Statistical analysis}

For the descriptive statistics, the categorical data were presented as percentage, whereas the continuous data were presented as mean and standard deviation (SD). We applied the weight for all analysis to ensure representativeness of the Korean population. For example, unweighted frequencies and weighted proportions with standard errors (SE) were presented for categorical data. Univariate and multiple logistic analyses were conducted to determine the effect of the risk factors (i.e. perceived level of stress, lifetime smoking status, smoking status regardless of exposure to secondhand smoke, smoking status including exposure to secondhand smoke, alcohol, obesity, residence, income, marital status, and educational level) on menstrual cycle irregularity. Additionally, the effect of smoking on early menopause was investigated using univariate logistic or linear regression analysis. The survey procedure was incorporated into the logistic regression analysis so that the complex survey design and sample weight will be reflected. All the data were analyzed using the SAS program (ver. 9.4; SAS Institute, Cary, NC, USA). 


\section{Result}

The average age of women with both regular and irregular menstrual cycles was 36.4 (SD, \pm 8.5 ) and 37.0 (SD, \pm 11.1 ) years, respectively. Table 1 presents the characteristics of the participants with and without regular menstrual cycles.

Table 2 shows the factors affecting the menstrual cycle of premenopausal women. In the univariate analysis, age, smoking status, pack-year, body weight, alcohol, perceived level of stress, marital status, educational level, and modifiable risk factor scores were associated with irregular menstruation (Table 2). Pack-year did not show a dose-response relationship with irregular menstruation. The pack-year with the lower level from the median value was associated with higher odds ratios (ORs) of menstrual cycle irregularity than those on the upper level. Based on the results of multiple logistic regression analysis involving obesity and smoking status, obese women ( $\geq 25 \mathrm{BMI})$ showed higher risk of irregular menstruation than normal-weight women $\left(25-<30 \mathrm{~kg} / \mathrm{m}^{2}\right.$ $\mathrm{OR}=1.56,95 \% \mathrm{CI}=1.19-2.03 ; \geq 30 \mathrm{~kg} / \mathrm{m}^{2}, \mathrm{OR}=1.81$, $95 \% \mathrm{CI}=1.17-2.79)$. In the multiple logistic regression analysis that included age, behavior score, marital status, perceived stress, and educational level, $\geq 3$ modifiable risk factor score was significantly associated with menstrual cycle irregularity. Following the adjustments of modifiable risk factor scores, perceived stress and educational level were significantly associated with menstrual cycle irregularity. Women who responded their perceived stress as 'very much' had 1.74 times higher OR of menstrual cycle irregularity than women who did as 'little'. As educational level was lowered, the risk of menstrual cycle irregularity increased (elementary school and below (reference $=$ high school), OR $=2.07,95 \%$ $\mathrm{CI}=1.24-3.46)$.

Table 3 displays the association between smoking and early menopause. To assess the effect of smoking on the menopausal status, we divided the population into two groups: early menopause (menopause before 50 years old) and late menopause (menopause at 50 years old and above) groups. The average ages $( \pm S D)$ of the late and early menopause groups were $52.6 \pm 2.4$ and $45.5 \pm$ 3.8 years, respectively. The ex- and current smokers had 1.34 and 1.68 times higher ORs than the non-smokers. Specifically, the ex- and current smokers had had higher ORs in terms of the number of cigarettes smoked per day, age at smoking initiation, total pack-year, and packyear before menopause than the non-smokers, although a dose-response relationship was not observed. Furthermore, the current smokers had significantly lower mean menopausal age than the ex- and non-smokers, based on the result of the regression analysis. The current smokers had approximately $1.14(\mathrm{SE}=0.283)$ lower average menopausal age than the non-smokers.
Figure 1 shows the proportions of each menarche age by groups of early ( $<50$ years) and late menopause ( $\geq 50$ years). There was no difference in the menarche ages of the early and late menopause groups; thus, early menarche age was not a factor to accelerate the early menopause in our subjects.

\section{Discussion}

Our study investigated the various factors influencing the menstrual cycle and the effects of smoking on menopausal onset. In our study, the risk factors for menstrual cycle irregularity were perceived stress, obesity, smoking, and marital status. Furthermore, early initiation of smoking and high cigarette consumption were significantly associated with premature menopause based on the results of analyses using both logit and linear regression models. This study focused on modifiable risk factors, such as smoking, obesity, and perceived stress, and revealed the importance of these factors in the improvement of women's health.

With regard to stress, our study showed that high level of perceived stress was associated with high probability of menstrual cycle irregularity. A previous study conducted among 696 women aged 20-40 years revealed that menstrual cycle irregularity was associated with high chronic stress level [29]. Moreover, past studies that utilized special tools to check the stress level (i.e., $>20$ in the Perceived Stress Scale or Global Severity Index) of university students also indicated that stress was correlated with irregular menstruation [30, 31]. One theory that explained the mechanism through which stress affects the menstrual cycle involves the HPA axis. This theory suggests that a reduction in the HPA axis activity leads to the occurrence of menopause. When the stress level is high, the HPA axis activity is interrupted. Thus, women who are suffering from considerable stress may experience more irregularities in menstruation than those who are not under stress [32].

In the present study, women who had BMI of 25-30 or $\geq 30$ have high possibility of developing irregular menstruation. This finding is also consistent with those of previous studies on the association between irregular menstruation and obesity. For instance, one study that involved 14,779 women who were 19-23 years old showed that those with BMI of $<17,17-18.5,18.5-20$, $25-30$, and $>30$ had 1.6, 1.2, 1.2, 1.1, and 1.4 times higher probability of developing menstrual cycle irregularity, respectively, than those with BMI of 20-25 BMI [33]. Furthermore, another study conducted among 1095 female students in childbearing years (18-25 years old) in Taiwan demonstrated that women with BMI of $>27$ had 18.48 times higher risk of developing menstrual cycle irregularity than those with BMI of 18.5-23.9 [20]. Additionally, a study on irregular menstruation, which 
Table 1 Descriptive characteristics of premenopausal women by menstrual cycle regularity (KNHANES, 2010-2012)

\begin{tabular}{|c|c|c|c|c|c|c|c|c|c|}
\hline & \multicolumn{3}{|c|}{ Total $(n=4788)$} & \multicolumn{3}{|c|}{ Regular $(n=4103)$} & \multicolumn{3}{|c|}{ Irregular $(n=685)$} \\
\hline & $n$ & $\%$ & SE & $n$ & $\%$ & SE & $\mathrm{n}$ & $\%$ & SE \\
\hline \multicolumn{10}{|l|}{ Age, years } \\
\hline 19 to $<30$ & 1157 & 30.6 & 1.0 & 943 & 28.9 & 1.0 & 214 & 39.7 & 2.3 \\
\hline 30 to $<40$ & 1737 & 31.6 & 0.9 & 1568 & 33.4 & 1.0 & 169 & 21.6 & 1.8 \\
\hline$\geq 40$ & 1894 & 37.8 & 0.9 & 1592 & 37.7 & 1.0 & 302 & 38.7 & 2.1 \\
\hline \multicolumn{10}{|l|}{ Residence } \\
\hline Rural & 601 & 13.8 & 1.4 & 504 & 13.4 & 1.4 & 588 & 15.7 & 2.3 \\
\hline Urban & 4187 & 86.2 & 1.4 & 3599 & 86.6 & 1.4 & 97 & 84.3 & 2.3 \\
\hline \multicolumn{10}{|l|}{ Household income, quartiles } \\
\hline 1 & 1130 & 27.7 & 0.9 & 968 & 27.7 & 1.0 & 162 & 27.5 & 2.3 \\
\hline$\|$ & 1171 & 24.7 & 0.8 & 1024 & 25.4 & 0.9 & 147 & 21.2 & 1.9 \\
\hline III & 1203 & 23.9 & 0.8 & 1009 & 23.2 & 0.9 & 194 & 27.4 & 2.2 \\
\hline IV & 1236 & 22.6 & 0.9 & 1060 & 22.6 & 0.9 & 176 & 22.6 & 2.0 \\
\hline Missing data & 48 & 1.1 & 0.2 & 42 & 1.1 & 0.2 & 6 & 1.2 & 0.7 \\
\hline \multicolumn{10}{|l|}{ Marital status } \\
\hline Married & 3563 & 69.2 & 1.0 & 3090 & 70.6 & 1.0 & 473 & 61.4 & 2.2 \\
\hline Not married & 1225 & 30.8 & 1.0 & 1013 & 29.4 & 1.0 & 212 & 38.6 & 2.2 \\
\hline \multicolumn{10}{|l|}{ Educational level } \\
\hline Elementary school and below & 144 & 3.2 & 0.3 & 104 & 2.8 & 0.3 & 40 & 5.9 & 1.0 \\
\hline Middle school & 251 & 5.8 & 0.4 & 186 & 5.1 & 0.4 & 65 & 9.6 & 1.3 \\
\hline High school & 2183 & 48.4 & 1.0 & 1848 & 47.6 & 1.1 & 335 & 53.0 & 2.4 \\
\hline University and above & 2202 & 42.3 & 1.0 & 1959 & 44.3 & 1.1 & 243 & 31.2 & 2.2 \\
\hline Missing data & 8 & 0.2 & 0.1 & 6 & 0.2 & 0.1 & 2 & 0.4 & 0.3 \\
\hline \multicolumn{10}{|l|}{ Smoking status } \\
\hline Non-smoker & 4264 & 87.2 & 0.6 & 3663 & 87.6 & 0.6 & 601 & 85.2 & 1.6 \\
\hline Ex-smoker & 208 & 4.8 & 0.4 & 181 & 4.9 & 0.4 & 27 & 4.5 & 1.0 \\
\hline Current smoker & 316 & 8.0 & 0.5 & 259 & 7.6 & 0.5 & 57 & 10.3 & 1.5 \\
\hline \multicolumn{10}{|l|}{ Secondhand smoking } \\
\hline None & 1359 & 27.3 & 0.8 & 1174 & 27.6 & 0.9 & 185 & 25.3 & 2.0 \\
\hline$<1 \mathrm{~h}$ & 211 & 4.8 & 0.4 & 183 & 4.9 & 0.4 & 28 & 4.5 & 1.1 \\
\hline$\geq 1 \mathrm{~h}$ & 392 & 9.8 & 0.6 & 334 & 9.9 & 0.6 & 58 & 9.1 & 1.3 \\
\hline Missing data & 2826 & 58.1 & 0.9 & 2412 & 57.6 & 1.0 & 414 & 61.1 & 2.2 \\
\hline \multicolumn{10}{|l|}{ Cigarettes per day } \\
\hline Non-smoker & 4264 & 87.2 & 0.6 & 3663 & 87.6 & 0.6 & 601 & 85.2 & 1.6 \\
\hline$<20$ cigarettes & 478 & 11.7 & 0.6 & 400 & 11.3 & 0.6 & 78 & 13.7 & 1.6 \\
\hline$\geq 20$ cigarettes & 44 & 1.1 & 0.2 & 38 & 1.1 & 0.2 & 6 & 1.1 & 0.5 \\
\hline Missing data & 2 & 0.0 & 0.0 & 2 & 0.0 & 0.0 & & & \\
\hline \multicolumn{10}{|l|}{ Age at smoking initiation } \\
\hline Non-smoker & 4264 & 87.2 & 0.6 & 3663 & 87.6 & 0.6 & 601 & 85.2 & 1.6 \\
\hline$<20$ years & 242 & 6.5 & 0.5 & 199 & 6.2 & 0.5 & 43 & 8.1 & 1.3 \\
\hline$\geq 20$ years & 282 & 6.3 & 0.4 & 241 & 6.2 & 0.5 & 41 & 6.7 & 1.2 \\
\hline \multicolumn{10}{|l|}{ Pack-year } \\
\hline Non-smoker & 4264 & 87.2 & 0.6 & 3663 & 87.6 & 0.6 & 601 & 85.2 & 1.6 \\
\hline Above the median (2.5 pack-years) & 249 & 6.0 & 0.4 & 206 & 5.6 & 0.4 & 43 & 8.0 & 1.3 \\
\hline
\end{tabular}


Table 1 Descriptive characteristics of premenopausal women by menstrual cycle regularity (KNHANES, 2010-2012) (Continued)

\begin{tabular}{|c|c|c|c|c|c|c|c|c|c|}
\hline & \multicolumn{3}{|c|}{ Total $(n=4788)$} & \multicolumn{3}{|c|}{ Regular $(n=4103)$} & \multicolumn{3}{|c|}{ Irregular $(n=685)$} \\
\hline & $n$ & $\%$ & SE & $n$ & $\%$ & SE & $n$ & $\%$ & SE \\
\hline Below or equal to the median (2.5 pack-years) & 257 & 6.4 & 0.5 & 220 & 6.3 & 0.5 & 37 & 6.4 & 1.2 \\
\hline Missing data & 18 & 0.4 & 0.1 & 14 & 0.4 & 0.1 & 4 & 0.4 & 0.2 \\
\hline \multicolumn{10}{|l|}{ Alcohol consumption } \\
\hline None & 604 & 12.0 & 0.6 & 520 & 12.1 & 0.6 & 84 & 11.5 & 1.5 \\
\hline$\leq 1$ time per month & 2085 & 43.2 & 0.9 & 1783 & 42.7 & 0.9 & 302 & 45.9 & 2.1 \\
\hline 2-4 times a month & 1164 & 24.6 & 0.8 & 1003 & 25.2 & 0.8 & 161 & 21.2 & 1.9 \\
\hline 2-3 times a week & 456 & 9.7 & 0.6 & 396 & 9.9 & 0.6 & 60 & 8.8 & 1.3 \\
\hline$\geq 4$ times a week & 100 & 2.5 & 0.3 & 81 & 2.3 & 0.3 & 19 & 3.4 & 1.0 \\
\hline Missing data & 379 & 8.0 & 0.5 & 320 & 7.8 & 0.6 & 59 & 9.2 & 1.4 \\
\hline \multicolumn{10}{|l|}{ Body mass index } \\
\hline 0 to $<18.5 \mathrm{~kg} / \mathrm{m}^{2}$ & 443 & 10.0 & 0.5 & 388 & 10.2 & 0.6 & 55 & 9.3 & 1.3 \\
\hline 18.5 to $<23 \mathrm{~kg} / \mathrm{m}^{2}$ & 2521 & 51.0 & 1.0 & 2211 & 52.2 & 1.0 & 310 & 44.8 & 2.4 \\
\hline 23 to $<25 \mathrm{~kg} / \mathrm{m}^{2}$ & 807 & 17.0 & 0.6 & 689 & 17.1 & 0.7 & 118 & 16.0 & 1.6 \\
\hline 25 to $<30 \mathrm{~kg} / \mathrm{m}^{2}$ & 811 & 17.2 & 0.7 & 662 & 16.3 & 0.8 & 149 & 22.2 & 1.8 \\
\hline$\geq 30 \mathrm{~kg} / \mathrm{m}^{2}$ & 191 & 4.5 & 0.4 & 143 & 4.0 & 0.4 & 48 & 7.3 & 1.3 \\
\hline Missing data & 15 & 0.3 & 0.1 & 10 & 0.3 & 0.1 & 5 & 0.5 & 0.2 \\
\hline \multicolumn{10}{|l|}{ Perceived stress } \\
\hline Little & 396 & 8.0 & 0.5 & 347 & 8.2 & 0.5 & 49 & 7.1 & 1.2 \\
\hline A little & 2847 & 58.3 & 0.9 & 2477 & 59.3 & 0.9 & 370 & 52.8 & 2.3 \\
\hline Much & 1304 & 28.2 & 0.8 & 1086 & 27.4 & 0.9 & 218 & 32.1 & 2.1 \\
\hline Very much & 241 & 5.5 & 0.4 & 193 & 5.0 & 0.4 & 48 & 8.0 & 1.2 \\
\hline \multicolumn{10}{|l|}{ Modifiable risk factor score ${ }^{a}$} \\
\hline 0 & 450 & 9.38 & 0.52 & 399 & 9.8 & 0.58 & 51 & 7.04 & 1.24 \\
\hline 1 & 2452 & 54.6 & 0.97 & 2134 & 55.5 & 1.02 & 318 & 49.8 & 2.48 \\
\hline 2 & 925 & 21.3 & 0.77 & 787 & 21.1 & 0.86 & 138 & 22.4 & 1.92 \\
\hline$\geq 3$ & 568 & 14.72 & 0.7 & 454 & 13.7 & 0.7 & 114 & 20.7 & 1.99 \\
\hline
\end{tabular}

${ }^{a}$ The given scores were summed and categorized based on smoking status, obesity level, and drinking frequency. The given score of each variable was as follows: 0 point each for non-smokers, underweight to overweight ( 0 to $<25 \mathrm{BMI}$ ), and nondrinkers; 1 point each for ex-smokers, obesity I ( 25 to $<30)$, and $1-4$ times per month alcohol consumption frequency; and 2 points each current smoker, obesity II ( $\geq 30 \mathrm{BMI}$ ), and $\geq 2$ times a week alcohol consumption frequency

was defined as $>15$ days of menstrual cycle difference, that was conducted among 726 women showed that women with BMI of $>30$ had 2.61 times higher risk of developing irregular menstruation than those with BMI of 25-29.9 [22]. The mechanism behind the association between BMI and irregular menstruation may be attributed to low SHBG level and high testosterone and FAI levels. The present study showed that women who had higher BMI developed irregular menstruation caused by low SHBG level and high testosterone, FAI, and insulin levels. An increase in the BMI resulted to changes (either decrease or increase) in the value of SHBG $(-0.44)$, testosterone $(+0.17)$, FAI $(+0.42)$, and insulin $(+0.54)$ [22].

The univariate regression analysis revealed that smoking was correlated with irregular menstruation; however, this association was not found in the multivariable regression analysis. To determine the effect of smoking on menstrual cycle irregularity, we categorized the smoking-related factors into the following: lifetime smoking status, secondhand smoking, cigarettes per day, age at smoking initiation, and pack-year. The results of the univariate logistic regression analysis revealed a statistically significant association between smoking status and irregular menstruation. Specifically, the current smokers had 1.4 times higher prevalence of menstrual cycle irregularity than non-smokers. However, the multivariable logistic regression analysis did not show a statistically significant difference in the prevalence of menstrual cycle irregularity between non-smokers and current smokers. This difference may be explained by multicollinearity because various factors, such as perceived stress, obesity, and alcohol consumption, were correlated with smoking. 
Table 2 Factors affecting the menstrual cycle irregularity of premenopausal women (KNHANES, 2010-2012)

\begin{tabular}{|c|c|c|c|c|c|c|c|c|c|}
\hline \multirow{3}{*}{ Age, years } & \multicolumn{3}{|c|}{ Univariate logistic $(n=4788)$} & \multicolumn{3}{|c|}{ Multivariable $(n=4773)$} & \multicolumn{3}{|c|}{ Multivariable $(n=4388)$} \\
\hline & \multirow[t]{2}{*}{$\mathrm{OR}$} & \multicolumn{2}{|c|}{$95 \% \mathrm{Cl}$} & \multirow[t]{2}{*}{$\mathrm{OR}$} & \multicolumn{2}{|c|}{$95 \% \mathrm{Cl}$} & \multirow[t]{2}{*}{ OR } & \multicolumn{2}{|c|}{$95 \% \mathrm{Cl}$} \\
\hline & & & & & & & & & \\
\hline 19 to $<30$ & 1.00 & & & 1.00 & & & 1.00 & & \\
\hline 30 to $<40$ & 0.47 & 0.37 & 0.61 & 0.60 & 0.41 & 0.90 & 0.63 & 0.41 & 0.95 \\
\hline$\geq 40$ & 0.75 & 0.60 & 0.93 & 0.79 & 0.52 & 1.18 & 0.84 & 0.55 & 1.28 \\
\hline \multicolumn{10}{|l|}{ Residence } \\
\hline Rural & 1.00 & & & & & & & & \\
\hline Urban & 0.83 & 0.62 & 1.12 & & & & & & \\
\hline \multicolumn{10}{|l|}{ Household income, quartiles } \\
\hline 1 & 1.00 & & & & & & & & \\
\hline$\|$ & 0.84 & 0.63 & 1.12 & & & & & & \\
\hline III & 1.19 & 0.89 & 1.59 & & & & & & \\
\hline IV & 1.01 & 0.76 & 1.35 & & & & & & \\
\hline \multicolumn{10}{|l|}{ Marital status } \\
\hline Married & 1.00 & & & 1.00 & & & 1.00 & & \\
\hline Not married & 1.51 & 1.24 & 1.85 & 1.46 & 1.00 & 2.14 & 1.73 & 1.38 & 2.16 \\
\hline \multicolumn{10}{|l|}{ Educational level } \\
\hline Elementary school and below & 1.91 & 1.24 & 2.94 & 2.04 & 1.28 & 3.25 & 2.07 & 1.24 & 3.46 \\
\hline Middle school & 1.69 & 1.18 & 2.42 & 1.81 & 1.23 & 2.66 & 1.79 & 1.20 & 2.65 \\
\hline High school & 1.00 & & & 1.00 & & & 1.00 & & \\
\hline University and above & 0.63 & 0.50 & 0.79 & 0.65 & 0.51 & 0.82 & 0.60 & 0.47 & 0.76 \\
\hline \multicolumn{10}{|l|}{ Smoking status } \\
\hline Non-smoker & 1.00 & & & & & & & & \\
\hline Ex-smoker & 0.95 & 0.59 & 1.54 & 0.97 & 0.58 & 1.60 & & & \\
\hline Current smoker & 1.40 & 1.01 & 1.94 & 1.11 & 0.79 & 1.56 & & & \\
\hline \multicolumn{10}{|l|}{ Secondhand smoking } \\
\hline None & 1.00 & & & & & & & & \\
\hline$<1 \mathrm{~h}$ & 0.99 & 0.58 & 1.69 & & & & & & \\
\hline$\geq 1 \mathrm{~h}$ & 1.00 & 0.69 & 1.43 & & & & & & \\
\hline \multicolumn{10}{|l|}{ Cigarettes per day } \\
\hline Non-smoker & 1.00 & & & & & & & & \\
\hline$<20$ cigarettes & 1.24 & 0.93 & 1.65 & & & & & & \\
\hline$\geq 20$ cigarettes & 1.10 & 0.45 & 2.71 & & & & & & \\
\hline \multicolumn{10}{|l|}{ Age at smoking initiation } \\
\hline Non-smoker & 1.00 & & & & & & & & \\
\hline$<20$ years & 1.35 & 0.93 & 1.97 & & & & & & \\
\hline$\geq 20$ years & 1.10 & 0.74 & 1.64 & & & & & & \\
\hline \multicolumn{10}{|l|}{ Pack-year } \\
\hline Non-smoker & 1.00 & & & & & & & & \\
\hline Above the median (2.5 pack-years) & 1.45 & 1.01 & 2.10 & & & & & & \\
\hline Below or equal to the median (2.5 pack-years) & 1.04 & 0.67 & 1.61 & & & & & & \\
\hline \multicolumn{10}{|l|}{ Alcohol consumption } \\
\hline None & 1.00 & & & & & & & & \\
\hline$\leq 1$ time per month & 1.13 & 0.83 & 1.54 & & & & & & \\
\hline
\end{tabular}


Table 2 Factors affecting the menstrual cycle irregularity of premenopausal women (KNHANES, 2010-2012) (Continued)

\begin{tabular}{|c|c|c|c|c|c|c|c|c|c|}
\hline \multirow[b]{3}{*}{ 2-4 times a month } & \multicolumn{3}{|c|}{ Univariate logistic $(n=4788)$} & \multicolumn{3}{|c|}{ Multivariable $(n=4773)$} & \multicolumn{3}{|c|}{ Multivariable $(n=4388)$} \\
\hline & \multirow{2}{*}{$\frac{\mathrm{OR}}{0.89}$} & \multicolumn{2}{|c|}{$95 \% \mathrm{Cl}$} & \multirow[t]{2}{*}{ OR } & \multicolumn{2}{|l|}{$95 \% \mathrm{Cl}$} & \multirow[t]{2}{*}{$\mathrm{OR}$} & \multicolumn{2}{|l|}{$95 \% \mathrm{Cl}$} \\
\hline & & 0.62 & 1.26 & & & & & & \\
\hline 2-3 times a week & 0.94 & 0.60 & 1.46 & & & & & & \\
\hline$\geq 4$ times a week & 1.58 & 0.78 & 3.20 & & & & & & \\
\hline \multicolumn{10}{|l|}{ Body mass index } \\
\hline 0 to $<18.5 \mathrm{~kg} / \mathrm{m}^{2}$ & 1.06 & 0.73 & 1.55 & 0.92 & 0.62 & 1.36 & & & \\
\hline 18.5 to $<23 \mathrm{~kg} / \mathrm{m}^{2}$ & 1.00 & & & 1.00 & & & & & \\
\hline 23 to $<25 \mathrm{~kg} / \mathrm{m}^{2}$ & 1.09 & 0.82 & 1.43 & 1.11 & 0.84 & 1.49 & & & \\
\hline 25 to $<30 \mathrm{~kg} / \mathrm{m}^{2}$ & 1.58 & 1.23 & 2.04 & 1.56 & 1.19 & 2.03 & & & \\
\hline$\geq 30 \mathrm{~kg} / \mathrm{m}^{2}$ & 2.14 & 1.42 & 3.23 & 1.81 & 1.17 & 2.79 & & & \\
\hline \multicolumn{10}{|l|}{ Perceived stress } \\
\hline Little & 1.00 & & & 1.00 & & & 1.00 & & \\
\hline A little & 1.02 & 0.70 & 1.50 & 1.07 & 0.73 & 1.57 & 1.09 & 0.72 & 1.65 \\
\hline Much & 1.34 & 0.90 & 2.00 & 1.31 & 0.89 & 1.95 & 1.28 & 0.83 & 1.98 \\
\hline Very much & 1.83 & 1.12 & 3.01 & 1.73 & 1.05 & 2.86 & 1.74 & 1.02 & 2.99 \\
\hline \multicolumn{10}{|c|}{ Modifiable risk factor score ${ }^{a}$} \\
\hline 0 & & & & & & & 1.00 & & \\
\hline 1 & & & & & & & 1.13 & 0.75 & 1.70 \\
\hline 2 & & & & & & & 1.30 & 0.83 & 2.05 \\
\hline$\geq 3$ & & & & & & & 1.61 & 1.03 & 2.52 \\
\hline
\end{tabular}

$O R$ odds ratios, $\mathrm{Cl}$ confidence interval

${ }^{a}$ The given scores were summed and categorized based on smoking status, obesity level, and drinking frequency. The given score of each variable was as follows: 0 point each for non-smokers, underweight to overweight ( 0 to $<25 \mathrm{BMI})$, and nondrinkers; 1 point each for ex-smokers, obesity I ( 25 to $<30$ ), and $1-4$ times per month alcohol consumption frequency; and 2 points each current smoker, obesity II ( $\geq 30 \mathrm{BMI}$ ), and $\geq 2$ times a week alcohol consumption frequency

The univariate analysis also revealed an association between menopause and smoking, although a dose-response relationship with regard to the pack-year was not observed. Participants who smoked at younger and older age had a tendency to develop early menopause. A previous study conducted among 14,889 women who were 18-23 years old in Austria indicated that ex-smokers had 1.2 times higher risk of developing irregular menstruation than non-smokers. For current smokers, the higher the number of smoked cigarettes, the higher the risk to develop irregular menstruation [33]. The findings of several previous studies also supported the association between smoking and early menopause. For example, one study involving 543 participants showed that current smokers were 0.8 years younger than non-smokers; however, no statistically significant difference was observed in regard to secondhand smoking between ex-smokers and current smokers [34]. Additionally, another previous study conducted among women aged 45-55 years old in Massachusetts demonstrated that smokers experienced menopause was 1.8 years earlier than non-smokers [35].

Additionally, a study based on the US National Health and Nutrition Examination Survey III demonstrated that smoking elevated the risk of developing early menopause among 5029 women who were older than 25 years old [36]. A systematic review of 96 articles based on 109 studies reported a association between smoking and early menopause, although a clear association between the quantities of cigarettes smoked or smoking period was not observed [21]. Moreover, one study also analyzed the relationship between prenatal and childhood household smoke exposure or adult active smoking and early natural menopause. The results showed current smokers who had been smoking period for $>26$ years or $>10$ cigarettes/day had higher risk of developing early natural menopause than the other current smokers [37].

The association between smoking and menopause may be attributed to the development of a hypoestrogenic state that is induced by smoking. A study conducted from 1977 to 1984 among 5000 women who were 34 years old or above showed that smokers had 19\% lower level of estradiol based on urine test than nonsmokers after menopause [38]. Furthermore, a study that involved 603 premenopausal women demonstrated that current smokers had lower total estrogen metabolite (EM) levels than non-smokers. These participants were shown to have significantly lower levels of parent estrogens, such as estradiol, 1-methoxyestradiol (a metabolite 
Table 3 Effect of smoking on menopause among postmenopausal women (KNHANES, 2007-2014)

\begin{tabular}{|c|c|c|c|c|c|c|c|c|c|c|c|c|c|}
\hline \multirow[t]{3}{*}{ Variables } & \multicolumn{2}{|c|}{$\begin{array}{l}\text { Early menopause } \\
(<50 \text { years })\end{array}$} & \multicolumn{2}{|c|}{$\begin{array}{l}\text { Late menopause } \\
\text { ( } \geq 50 \text { years) }\end{array}$} & \multicolumn{3}{|c|}{$\begin{array}{l}\text { Logistic regression } \\
\text { for early menopause } \\
(<50 \text { years })^{\mathrm{a}}\end{array}$} & \multicolumn{3}{|c|}{$\begin{array}{l}\text { Linear regression for } \\
\text { menopausal age } \\
\text { (categorical variable) }\end{array}$} & \multicolumn{3}{|c|}{$\begin{array}{l}\text { Linear regression for } \\
\text { menopausal age } \\
\text { (continuous variable) }^{\text {a }}\end{array}$} \\
\hline & \multirow{2}{*}{$\begin{array}{l}\mathrm{n} \\
\text { (mean) }\end{array}$} & \multirow{2}{*}{$\begin{array}{l}\% \\
(\mathrm{SD})\end{array}$} & \multirow{2}{*}{$\begin{array}{l}\mathrm{n} \\
\text { (mean) }\end{array}$} & & \multirow[t]{2}{*}{ OR } & \multicolumn{2}{|c|}{$95 \% \mathrm{Cl}$} & \multirow[t]{2}{*}{$\bar{\beta}$} & \multirow[t]{2}{*}{ SE } & \multirow[t]{2}{*}{$p$-value } & \multirow[t]{2}{*}{$\beta$} & \multirow[t]{2}{*}{ SE } & \multirow[t]{2}{*}{$p$-value } \\
\hline & & & & & & & & & & & & & \\
\hline Total & 4930 & 45.9 & 5767 & 54.1 & & & & & & & & & \\
\hline Current age, mean (SD) & 64.5 & 0.2 & 62.8 & 0.2 & & & & & & & & & \\
\hline Average menopausal age, mean (SD) & 45.6 & 0.1 & 52.5 & 0.0 & & & & & & & & & \\
\hline \multicolumn{14}{|l|}{ Smoking status } \\
\hline Non-smoker & 4447 & 90.6 & 5343 & 93.6 & 1.00 & & & 1.000 & & & & & \\
\hline Ex-smoker & 172 & 3.7 & 160 & 2.9 & 1.34 & 1.02 & 1.77 & -0.615 & 0.365 & 0.093 & & & \\
\hline Current smoker & 236 & 5.7 & 175 & 3.5 & 1.68 & 1.30 & 2.17 & -1.137 & 0.283 & $<.0001$ & & & \\
\hline Total & 4855 & 100.0 & 5678 & 100.0 & & & & & & & & & \\
\hline \multicolumn{14}{|l|}{ Cigarettes per day } \\
\hline Non-smoker & 4447 & 92.3 & 5343 & 95.1 & 1.00 & & & 1.000 & & & & & \\
\hline$<20$ cigarettes & 268 & 6.1 & 205 & 3.9 & 1.61 & 1.26 & 2.07 & -1.104 & 0.302 & 0.000 & & & \\
\hline$\geq 20$ cigarettes & 69 & 1.5 & 55 & 1.0 & 1.53 & 1.00 & 2.33 & -0.486 & 0.444 & 0.274 & & & \\
\hline Total & 4784 & 100.0 & 5603 & 100.0 & & & & & & & -0.038 & 0.019 & 0.046 \\
\hline \multicolumn{14}{|l|}{ Age at smoking initiation ${ }^{b}$} \\
\hline Non-smoker & 3409 & 89.9 & 3993 & 93.1 & 1.00 & & & 1.000 & & & & & \\
\hline$<20$ years & 36 & 1.2 & 15 & 0.4 & 2.93 & 1.45 & 5.90 & -1.438 & 0.461 & 0.002 & & & \\
\hline$\geq 20$ years & 298 & 8.9 & 246 & 6.4 & 1.43 & 1.13 & 1.82 & -0.827 & 0.293 & 0.005 & & & \\
\hline Total & 3743 & 100.0 & 4254 & 100.0 & & & & & & & -0.004 & 0.001 & $<.0001$ \\
\hline \multicolumn{14}{|l|}{ Pack-year (total) ${ }^{\text {b }}$} \\
\hline Non-smoker & 3409 & 90.2 & 3993 & 93.4 & 1.00 & & & & & & & & \\
\hline $\begin{array}{l}\text { Below or equal to the median } \\
\text { ( } \leq 9.8 \text { pack-years) }\end{array}$ & 153 & 4.9 & 175 & 3.4 & 1.50 & 1.11 & 2.01 & -0.773 & 0.342 & 0.024 & & & \\
\hline Above the median ( $>9.8$ pack-years) & 172 & 4.9 & 78 & 3.3 & 1.57 & 1.17 & 2.09 & -1.037 & 0.389 & 0.008 & & & \\
\hline Total & 3734 & 100.0 & 4246 & 100.0 & & & & & & & -0.025 & 0.015 & 0.103 \\
\hline \multicolumn{14}{|l|}{ Pack-year (before menopause) ${ }^{b}$} \\
\hline Non-smoker & 3409 & 92.0 & 3993 & 93.7 & 1.00 & & & 1.000 & & & & & \\
\hline $\begin{array}{l}\text { Below or equal to the median ( } \leq 5 \\
\text { pack-years) }\end{array}$ & 133 & 4.0 & 107 & 2.7 & 1.54 & 1.11 & 2.13 & -1.076 & 0.370 & 0.004 & & & \\
\hline Above the median ( $>5$ pack-years) & 123 & 4.0 & 131 & 3.6 & 1.14 & 0.83 & 1.57 & 0.417 & 0.340 & 0.220 & & & \\
\hline Total & 3665 & 100.0 & 4231 & 100.0 & & & & & & & 0.035 & 0.020 & 0.077 \\
\hline
\end{tabular}

of the 2-hydroxylation pathway), estriol (an EM of the 16-hydroxylation pathway), and 16-epiestriol [39]. Moreover, one study conducted from 1982 to 1984 among 350 women aged 45-69 years revealed that smokers use 1.46 times more hormonal replacement therapy (HRT) than non-smokers $(\mathrm{OR}=1.46, p=0.005)$. On the other hand, the use of HRT was not statistically significant among ex-smokers. HRT is used when the estrogen level becomes low. Therefore, the increase use of HRT among smokers than non-smokers indicated that smoking induces hypoestrogenic state [40]. Another mechanism through which smoking induces hypoestrogenic state involves the increase in the level of HPA axis hormones, including adrenocorticotropic hormone, cortisol, and dehydroepiandrosterone, such as during stress [41].

The association between alcohol consumption and menstrual cycle irregularity was not found to be statistically significant. However, when we considered the behavioral patterns such as smoking status, obesity level, and alcohol consumption, these negative behaviors were significantly associated with the increased prevalence of menstrual cycle irregularity. While, smoking was inversely related to obesity, alcohol consumption could result in increasing the prevalence of 
obesity. Therefore, it may be plausible to consider the integration of behaviors when investigating menstrual cycle irregularity.

Menarche age was not significantly different between women who attained menopause before or after the age of 50 years. Some debates still exist on the relationship between menarche and menopausal ages. Women who began their menstruation at the age of 11 years or younger have an $80 \%$ higher chance of having menopause at the age of 40 years than those who started menstruating at the age of 13 years. Additionally, the risk of having menopause at the age of 40-44 years was approximately $30 \%$ [42]. However, our study indicated that premature menopause may be caused by acquired and environmental factors, rather than the menarche age. Hence, further research on this topic would be necessary [43, 44].

Our study has several limitations to consider when interpreting the results. First, because our study used cross-sectional data, causal relationships could not be determined. Second, most data on the participants' characteristics were collected through self-reported questionnaires, except for BMI. Third, when assessing the factors affecting menopause, we could not consider other factors, except for smoking, because information regarding the participants' at the time of their menopausal age was not available.

\section{Conclusion}

Our study results showed the importance of healthier behavioral practices to maintain menstrual cycle regularity, especially when considering that smoking may be associated with the occurrence of early menopause. Given the association between early menopause or irregular menstruation and women's health, improvements in health behaviors should be emphasized in view of public health.

\section{Acknowledgements}

Not applicable.

\section{Funding}

This research was supported by a grant of the Korea Health Technology R\&D Project through the Korea Health Industry Development Institute (KHIDI), funded by the Ministry of Health \& Welfare, Republic of Korea (grant number: HC15C1322). The funders had no role in study design, data collection and analysis, decision to publish, or preparation of the manuscript.

\section{Availability of data and materials}

Data are available through the website of the KCDC. https://knhanes.cdc.go.kr/ knhanes/sub03/sub03_02_02.do

\section{Authors' contributions}

JJ Bae and S Park analyzed the data and wrote the manuscript, and JW Kwon designed the study and participated in writing the manuscript. All authors read and approved the final manuscript.

\section{Ethics approval and consent to participate}

The Korea National Health and Nutrition Examination Survey (KNHANES) was approved by the Ethics Committee of the Korea Centers for Disease Control \& Prevention (2007-02CON-04-P, 2008-04EXP-01-C, 2009-01CON-03-2C, 2010-
02CON-21-C, 2011-02CON-06-C, 2012-01EXP-01-2C, 2013-07CON-03-4C, and 2013-12EXP-03-5C). All study participants provided a written informed consent to agree the data to be used in national statistics and research. The KNHANES data is open to the public after anonymization.

\section{Consent for publication}

Not applicable as this manuscript does not include details, images, or videos relating to individual participants.

\section{Competing interests}

The authors declare that they have no competing interests.

\section{Publisher's Note}

Springer Nature remains neutral with regard to jurisdictional claims in published maps and institutional affiliations.

Received: 24 August 2017 Accepted: 29 January 2018

Published online: 06 February 2018

References

1. Rahman I, Akesson A, Wolk A. Relationship between age at natural menopause and risk of heart failure. Menopause. 2015;22:12-6.

2. Atsma F, M-LE B, Grobbee DE, van der Schouw YT. Postmenopausal status and early menopause as independent risk factors for cardiovascular disease: a meta-analysis. Menopause. 2006;13:265-79.

3. Gallagher JC. Effect of early menopause on bone mineral density and fractures. Menopause. 2007;14:567-71.

4. Solomon CG, Hu FB, Dunaif A, Rich-Edwards J, Willett WC, Hunter DJ, et al. Long or highly irregular menstrual cycles as a marker for risk of type 2 diabetes mellitus. JAMA. 2001;286:2421-6.

5. Solomon CG, Hu FB, Dunaif A, Rich-Edwards JE, Stampfer MJ, Willett WC, et al. Menstrual cycle irregularity and risk for future cardiovascular disease. J Clin Endocrinol Metab. 2002;87:2013-7.

6. Kato I, Toniolo P, Koenig KL, Shore RE, Zeleniuch-Jacquotte A, Akhmedkhanov A, et al. Epidemiologic correlates with menstrual cycle length in middle aged women. Eur J Epidemiol. 1999;15:809-14.

7. Waller K, Swan SH, Windham GC, Fenster L, Elkin EP, Lasley BL. Use of urine biomarkers to evaluate menstrual function in healthy premenopausal women. Am J Epidemiol. 1998;147:1071-80.

8. Van Voorhis BJ, Santoro N, Harlow S, Crawford SL, Randolph J. The relationship of bleeding patterns to daily reproductive hormones in women approaching menopause. Obstet Gynecol. 2008;112:101-8.

9. Mumford SL, Steiner AZ, Pollack AZ, Perkins NJ, Filiberto AC, Albert PS, et al. The utility of menstrual cycle length as an indicator of cumulative hormonal exposure. J Clin Endocrinol Metab. 2012;97:E1871-9.

10. Reindollar RH, Novak M, Tho SP, McDonough PG. Adult-onset amenorrhea: a study of 262 patients. Am J Obstet Gynecol. 1986;155:531-41.

11. Loucks $A B$, Thuma JR. Luteinizing hormone pulsatility is disrupted at a threshold of energy availability in regularly menstruating women. J Clin Endocrinol Metab. 2003;88:297-311.

12. Liu JH. Hypothalamic amenorrhea: clinical perspectives, pathophysiology, and management. Am J Obstet Gynecol. 1990;163:1732-6.

13. Berga S, Naftolin F. Neuroendocrine control of ovulation. Gynecol Endocrinol. 2012;28(Supple1):9-13.

14. Cooper GS, Ephross SA, Weinberg CR, Baird DD, Whelan EA, Sandler DP. Menstrual and reproductive risk factors for ischemic heart disease. Epidemiology. 1999:10:255-9.

15. Friday KE, Dong C, Fontenot RU. Conjugated equine estrogen improves glycemic control and blood lipoproteins in postmenopausal women with type 2 diabetes. J Clin Endocrinol Metab. 2001;86:48-52.

16. La Vecchia C, Decarli A, Franceschi S, Gentile A, Negri E, Parazzini F. Menstrual and reproductive factors and the risk of myocardial infarction in women under fifty-five years of age. Am J Obstet Gynecol. 1987;157:1108-12.

17. Westhoff C, Gentile G, Lee J, Zacur H, Helbig D. Predictors of ovarian steroid secretion in reproductive-age women. Am J Epidemiol. 1996;144:381-8.

18. Maniam J, Antoniadis C, Morris MJ. Early-life stress, HPA axis adaptation, and mechanisms contributing to later health outcomes. Front Eendocrinol. 2014; $5: 73$.

19. Freeman EW, Sammel MD, Lin H, Gracia CR. Obesity and Reproductive hormone levels in the transition to menopause. Menopause. 2010;17: $718-26$. 
20. Chang PJ, Chen PC, Hsieh CJ, Chiu LT. Risk factors on the menstrual cycle of healthy Taiwanese college nursing students. Aust N Z J Obstet Gynaecol. 2009;49:689-94.

21. Parente RC, Faerstein E, Celeste RK, Werneck GL. The relationship between smoking and age at the menopause: a systematic review. Maturitas. 2008; 61:287-98.

22. Wei S, Schmidt MD, Dwyer T, Norman RJ, Venn AJ. Obesity and menstrual irregularity: associations with SHBG, testosterone, and insulin. Obesity. 2009; 17:1070-6.

23. Ju H, Jones M, Mishra GD. A U-shaped relationship between body mass index and dysmenorrhea: a longitudinal study. PLoS One. 2015;10:e0134187.

24. Dars S, Sayed K, Relationship YZ. Of menstrual irregularities to BMI and nutritional status in adolescent girls. Pak J Med Sci. 2014;30:141-4.

25. Lee SS, Kim DH, Nam G-E, Nam H-Y, Kim YE, Lee SH, et al. Association between metabolic syndrome and menstrual irregularity in middle-aged Korean women. Korean J Fam Med. 2016;37:31-6.

26. James PT, Leach R, Kalamara E, Shayeghi M. The worldwide obesity epidemic. Obes Res. 2001;9(Suppl 4):228-33.

27. $\mathrm{Ng} \mathrm{M}$, Freeman MK, Fleming TD, Robinson M, Dwyer-Lindgren $L$, Thomson $B$, et al. Smoking prevalence and cigarette consumption in 187 countries, 1980-2012. JAMA. 2014;311:183-92.

28. Kweon S, Kim Y, M-j J, Kim Y, Kim K, Choi S, et al. Data resource profile: the Korea National Health and nutrition examination survey (KNHANES). Int J Epidemiol. 2014;43:69-77.

29. Palm-Fischbacher S, Ehlert U. Dispositional resilience as a moderator of the relationship between chronic stress and irregular menstrual cycle. J Psychosom Obstet Gynaecol. 2014;35:42-50.

30. Nagma S, Kapoor G, Bharti R, Batra A, Batra A, Aggarwal A, et al. To evaluate the effect of perceived stress on menstrual function. J Clin Diagn Res. 2015; 9:QC01-3.

31. Delara M, Woodgate RL. Psychological distress and its correlates among university students: a cross-sectional study. J Pediatr Adolesc Gynecol. 2015; 28(4):240.

32. Kalantaridou SN, Makrigiannakis A, Zoumakis E, Chrousos GP. Stress and the female reproductive system. J Reprod Immunol. 2004;62:61-8.

33. Mishra GD, Dobson AJ, Schofield MJ. Cigarette smoking, menstrual symptoms and miscarriage among young women. Aust N Z J Public Health. 2000;24:413-20.

34. Cooper GS, Sandler DP, Bohlig M. Active and passive smoking and the occurrence of natural menopause. Epidemiology. 1999:10:771-3.

35. Mckinlay SM, Brambilla DJ, Posner JG. "Reprint of" the normal menopause transition. Maturitas. 2008;61:4-16.

36. Fleming LE, Levis S, LeBlanc WG, Dietz NA, Arheart KL, Wilkinson JD, et al. Earlier age at menopause, work and tobacco smoke exposure. Menopause. 2008;15:1103-8.

37. Tawfik H, Kline J, Jacobson J, Tehranifar P, Protacio A, Flom JD, et al. Life course exposure to smoke and early menopause and menopausal transition. Menopause. 2015;22:1076-83.

38. MacMahon B, Trichopoulos D, Cole P, Brown J. Cigarette smoking and urinary estrogens. N Engl J Med. 1982;307:1062-5.

39. Gu F, Caporaso NE, Schairer C, Fortner RT, Xu X, Hankinson SE, et al. Urinary concentrations of estrogens and estrogen metabolites and smoking in caucasian women. Cancer Epidemiol Biomark Prev. 2013;22:58-68.

40. Greenberg G, Thompson S, Meade T. Relation between cigarette smoking and use of hormonal replacement therapy for menopausal symptoms. J Epidemiol Community Health. 1987;41:26-9.

41. Goletiani NV, Siegel AJ, Lukas SE, Hudson Jl. The effects of smoked nicotine on measures of subjective states and hypothalamic-pituitary-adrenal axis hormones in women during the follicular and luteal phases of the menstrual cycle. J Addict Med. 2015;9:195-203.

42. Mishra G, Pandeya N, Dobson A, Chung H, Anderson D, Kuh D, et al. Early menarche, Nulliparity, and the risk for premature and early natural menopause. Hum Reprod. 2017;32:679-86.

43. Gold EB. The timing of the age at which natural menopause occurs. Obstet Gynecol Clin N Am. 2011;38:425-40.

44. Gold EB, Bromberger J, Crawford S, Samuels S, Greendale GA, Harlow SD, et al. Factors associated with age at natural menopause in a multiethnic sample of midlife women. Am J Epidemiol. 2001;153:865-74.

\section{Submit your next manuscript to BioMed Central and we will help you at every step:}

- We accept pre-submission inquiries

- Our selector tool helps you to find the most relevant journal

- We provide round the clock customer support

- Convenient online submission

- Thorough peer review

- Inclusion in PubMed and all major indexing services

- Maximum visibility for your research

Submit your manuscript at www.biomedcentral.com/submit
Biomed Central 